\title{
Potencial agrícola do uso de resíduo de indústria de carnes em Latossolo Vermelho ${ }^{1}$
}

\author{
André Somavilla ${ }^{2}$, Vanderlei Rodrigues da Silva ${ }^{3}$, \\ Clovis Orlando Da Ros ${ }^{3}$, Moacir Tuzzin de Moraes ${ }^{4}$, Felipe Bonini da Luz ${ }^{3}$
}

\begin{abstract}
Agricultural potential use of organic

waste from meat industry in a Rhodic Hapludox

The use of non-renewable sources for the production of mineral fertilizers causes major impacts to the environment. The reduction of these impacts favors the increasing search for new organic nutrient sources for crops. This study aimed to evaluate the use of residue from meat industry (RMI) as an alternative source of nutrients for sunflower and maize crops. Five doses of RMI $\left(0 \mathrm{~m}^{3} \mathrm{ha}^{-1}, 25 \mathrm{~m}^{3} \mathrm{ha}^{-1}, 50 \mathrm{~m}^{3} \mathrm{ha}^{-1}, 75 \mathrm{~m}^{3} \mathrm{ha}^{-1}\right.$ and $\left.100 \mathrm{~m}^{3} \mathrm{ha}^{-1}\right)$ and one treatment with mineral fertilization were tested. The RMI provided an increase in grain yield for the sunflower and maize crops. In the maize crop, the highest yield was obtained with the dose of $87 \mathrm{~m}^{3} \mathrm{ha}^{-1}$ of RMI, equivalent to $92 \%$ of the yield obtained with mineral fertilization. In the sunflower crop, doses equal to or higher than $20 \mathrm{~m}^{3} \mathrm{ha}^{-1}$ of RMI provided equal or higher yields than those obtained with mineral fertilization. The RMI presented agricultural potential for use as an organic fertilizer and can partially or totally replace chemical fertilization.
\end{abstract}

KEY-WORDS: Zea mays L.; Helianthus annuus L.; organic fertilization.

\section{INTRODUÇÃO}

A região Sul do Brasil é responsável por 44,4\% da produção nacional de milho (IBGE 2011), que é a principal cultura da cadeia produtiva de suínos, aves e leite.

O girassol também é uma cultura que está se destacando em área de cultivo na região, com o objetivo principal da obtenção de óleo comestível, pois os aquênios são ricos em ácidos graxos poli-insaturados (Tsuzuki et al. 2003) e ácido linoleico (Fernandes et al. 2008). O girassol apresenta perspectivas promis-

\section{RESUMO}

A utilização de fontes não renováveis, para a produção de adubos minerais, causa grandes impactos ao meio ambiente. A redução desses impactos é favorecida pela crescente busca por novas fontes nutricionais orgânicas, para as culturas. Este trabalho objetivou avaliar a utilização de resíduo de indústria de carnes (RIC) como fonte alternativa de nutrientes para as culturas do girassol e milho. Foram utilizadas cinco doses de RIC (0 m ha ${ }^{-1}, 25 \mathrm{~m}^{3}$ ha $^{-1}, 50 \mathrm{~m}^{3} \mathrm{ha}^{-1}, 75 \mathrm{~m}^{3} \mathrm{ha}^{-1}$ e $\left.100 \mathrm{~m}^{3} \mathrm{ha}^{-1}\right)$ e um tratamento com adubação mineral. O RIC proporcionou aumento na produtividade de grãos das culturas de girassol e milho. Na cultura do milho, a máxima produtividade foi obtida com a dose de $87 \mathrm{~m}^{3} \mathrm{ha}^{-1}$ de RIC, equivalendo a $92 \%$ da produtividade obtida com a adubação mineral. Na cultura do girassol, doses iguais ou superiores a $20 \mathrm{~m}^{3} \mathrm{ha}^{-1}$ de RIC proporcionaram produtividades iguais ou superiores às obtidas com adubação mineral. O RIC apresentou potencial agrícola para uso como fertilizante orgânico, podendo substituir, parcial ou totalmente, a adubação química.

PALAVRAS-CHAVE: Zea mays L.; Helianthus annuus L.; adubação orgânica.

soras na produção nacional de grãos, demonstrando possibilidades de ser amplamente cultivado no território brasileiro.

O potencial produtivo dessas culturas é atribuído ao somatório das manifestações dos fatores genéticos e presença de ambiente com condições favoráveis e de manejos adequados, que visam à máxima produção (Bugbee \& Salisbury 1988). Nesse contexto, os solos tropicais apresentam elevado grau de intemperização, acarretando baixa disponibilidade de nutrientes ao perfil do solo, sendo esse um dos fatores mais limitantes à produtividade das culturas.

1. Trabalho recebido em ago./2013 e aceito para publicação em ago./2014 ( $\mathrm{n}^{\mathrm{o}}$ registro: PAT 26171).

2. Universidade Federal de Santa Maria (UFSM), Departamento de Solos, Santa Maria, RS, Brasil. E-mail: andre.s.1992@hotmail.com.

3. Universidade Federal de Santa Maria (UFSM), Departamento de Ciências Agronômicas e Ambientais, Frederico Westphalen, RS, Brasil.E-mails: vanderlei@ufsm.br, clovisdaros@ufsm.br, fe_bonini.luz@hotmail.com.

4. Universidade Federal do Rio Grande do Sul (UFRGS), Departamento de Solos, Porto Alegre, RS, Brasil.

E-mail: moacir.tuzzin@gmail.com. 
Quantidades elevadas de nutrientes exigidos pelas plantas, para maximizar a produção, dificilmente são supridas exclusivamente pelo solo, necessitando-se, assim, de formas suplementares de adubação. O nitrogênio é o nutriente mais limitante para as culturas do milho e girassol, por apresentar maior influência sobre a produtividade e a qualidade dos grãos (Gastal \& Lemaire 2002, Biscaro et al. 2008), além de ser componente importante no custo de produção da cultura do milho (Aita et al. 2001).

A adubação mineral é atualmente a forma mais utilizada para suprir a demanda nutricional das plantas. Porém, muitos materiais de origem orgânica, tais como o lodo de esgoto (Lobo et al. 2012), dejetos líquidos de suínos (Giacomini \& Aita 2008, Doblinski et al. 2010) e bovinos (Pauletti et al. 2008, Silveira et al. 2011), além de resíduos orgânicos de agroindústrias (Moraes et al. 2012), podem vir a se tornar fontes alternativas para suprir total ou parcialmente as necessidades nutricionais das culturas. No entanto, os resíduos orgânicos geralmente possuem baixa concentração de nutrientes, necessitando-se da aplicação de grandes volumes para satisfazer às exigências das plantas.

Nesse contexto, este trabalho objetivou avaliar o potencial fertilizante de resíduos de indústria de carnes, nas culturas do girassol e milho, em um Latossolo Vermelho.

\section{MATERIAL E MÉTODOS}

O experimento foi conduzido em condições de campo, nos anos agrícolas de 2009/2010 e 2010/2011, em área experimental do Departamento de Ciências Agronômicas e Ambientais da Universidade Federal de Santa Maria, em Frederico Westphalen, região norte do Estado do Rio Grande do Sul (27\%23'46"S, $53^{\circ} 25^{\prime} 32^{\prime \prime} \mathrm{W}$ e altitude de $480 \mathrm{~m}$ ). O clima, segundo a classificação de Köppen, é subtropical úmido, sem estiagens, tipo Cfa.

O solo é classificado como Latossolo Vermelho aluminoférrico típico, com textura muito argilosa. Os atributos químicos e físicos, verificados na camada superficial $(0-10 \mathrm{~cm})$, antes da instalação do experimento, foram: $65 \%$ de argila; $\mathrm{pH}$ em água de 5,1; índice SMP de 6,2; 7,6 $\mathrm{mg} \mathrm{dm}^{-3}$ de P; $280 \mathrm{mg} \mathrm{dm}^{-3}$ de $\mathrm{K} ; 0,2 \mathrm{cmol}_{\mathrm{c}} \mathrm{dm}^{-3}$ de Al; $5,5 \mathrm{cmol}_{\mathrm{c}} \mathrm{dm}^{-3} \mathrm{de} \mathrm{Ca}$; $1,6 \mathrm{cmol}_{\mathrm{c}} \mathrm{dm}^{-3} \mathrm{de} \mathrm{Mg} ; 11,1 \mathrm{mg} \mathrm{dm}^{-3} \mathrm{de} \mathrm{S} ; 5,8 \mathrm{mg} \mathrm{dm}^{-3}$ de $\mathrm{Cu} ; 1,8 \mathrm{mg} \mathrm{dm}^{-3} \mathrm{de} \mathrm{Zn} ; 3,5 \mathrm{cmol}_{\mathrm{c}} \mathrm{dm}^{-3} \mathrm{de} \mathrm{H}+\mathrm{Al}$; $8 \mathrm{cmol}_{\mathrm{c}} \mathrm{dm}^{-3}$ de CTC efetiva; $11,5 \mathrm{cmol}_{\mathrm{c}} \mathrm{dm}^{-3} \mathrm{de}$ CTC potencial; $2 \%$ de saturação por $\mathrm{Al} ; 69 \%$ de saturação por bases; e 2,2\% de matéria orgânica.

$\mathrm{O}$ delineamento experimental utilizado foi o de blocos completos casualizados, com três repetições, em parcelas com área de $16 \mathrm{~m}^{2}(4 \mathrm{~m} \mathrm{x} 4 \mathrm{~m})$. Os tratamentos foram doses de $0 \mathrm{~m}^{3} \mathrm{ha}^{-1}, 25 \mathrm{~m}^{3} \mathrm{ha}^{-1}$, $50 \mathrm{~m}^{3}$ ha $^{-1}, 75 \mathrm{~m}^{3} \mathrm{ha}^{-1}$ e $100 \mathrm{~m}^{3}$ ha $^{-1}$ de resíduos de indústria de carnes (RIC), além de um tratamento com adubação mineral (NPK) (CQFS-RS/SC 2004). O resíduo foi aplicado em duas épocas: a primeira em 2009, aos 45 dias antes da semeadura da cultura do girassol, e a segunda em 2010, aos 30 dias antes da semeadura do milho.

O RIC foi proveniente de uma agroindústria localizada em Frederico Westphalen (RS). O material é resultado da compostagem e estabilização química de resíduos da agroindústria de suínos, contendo graxas, óleos, resíduos da queima de madeira, hidróxido de cálcio (cal hidratada) e serragem de madeira. A caracterização química do resíduo foi realizada pela técnica de Espectrometria de Fluorescência de Raios X por Energia Dispersiva (EDXFR) (Wastowski et al. 2010), após o material ter sido seco em estufa, a $65^{\circ} \mathrm{C}$. Os valores encontrados foram: $229 \mathrm{~g} \mathrm{~kg}^{-1} \mathrm{de}$ $\mathrm{Ca} ; 40 \mathrm{~g} \mathrm{~kg}^{-1}$ de P; $15 \mathrm{~g} \mathrm{~kg}^{-1}$ de K; $15 \mathrm{~g} \mathrm{~kg}^{-1}$ de Si; $13 \mathrm{~g} \mathrm{~kg}^{-1}$ de Fe; $3,5 \mathrm{~g} \mathrm{~kg}^{-1}$ de S; 0,6 $\mathrm{g} \mathrm{kg}^{-1}$ de Mn; e $0,2 \mathrm{~g} \mathrm{~kg}^{-1} \mathrm{de} \mathrm{Zn}$. Os teores de $\mathrm{N}$ total e $\mathrm{N}$ mineral foram determinados conforme metodologia de Tedesco et al. (1995), contendo teores de $6,6 \mathrm{~g} \mathrm{~kg}^{-1}$ de $\mathrm{N}$ total, $130 \mathrm{mg} \mathrm{kg}^{-1}$ de $\mathrm{N}^{-\mathrm{NH}_{4}^{+}}$e $670 \mathrm{mg} \mathrm{kg}^{-1} \mathrm{de} \mathrm{N}^{-\mathrm{NO}_{3}^{-}}$. Na Tabela 1, estão especificadas as quantidades médias de nutrientes aplicadas, por cultura, em função das doses de RIC.

O girassol, híbrido simples (cultivar HLA203 Clearfield), foi semeado no dia 10 de dezembro de 2009, prevendo-se população final de 35.000 plantas ha $^{-1}$, com espaçamento entre as linhas de $0,80 \mathrm{~m}$. No tratamento com NPK, foi utilizada adubação para uma expectativa de rendimento de grãos de $2.000 \mathrm{~kg} \mathrm{ha}^{-1}$ (CQFS-RS/SC 2004). Foram aplicados, na semeadura, $10 \mathrm{~kg} \mathrm{ha}^{-1} \mathrm{de} \mathrm{N}, 30 \mathrm{~kg} \mathrm{ha}^{-1}$ de $\mathrm{P}_{2} \mathrm{O}_{5}$ e $30 \mathrm{~kg} \mathrm{ha}^{-1}$ de $\mathrm{K}_{2} \mathrm{O}$, na forma de ureia, superfosfato triplo e cloreto de potássio, respectivamente. Em cobertura, aos 30 dias após a emergência, foram aplicados $50 \mathrm{~kg} \mathrm{ha}^{-1}$ de N, na forma de ureia, a lanço e sem incorporação ao solo. Durante o desenvolvimento do girassol, ocorreu precipitação total de $489 \mathrm{~mm}$ (Figura 1a), considerada suficiente para a cultura, a qual necessita de 400-500 mm (Castro \& Farias 2005). 
Tabela 1. Aporte de nutrientes, por cultivo, com a aplicação de resíduo orgânico de efluente de indústria de carnes (RIC), nas culturas do girassol e milho (Frederico Westphalen, RS, 2014).

\begin{tabular}{|c|c|c|c|c|c|c|c|c|c|}
\hline \multirow{2}{*}{ Dose de $\mathrm{RIC}^{(1)}$} & \multicolumn{2}{|c|}{$\mathrm{N}$ mineral ${ }^{(2)}$} & \multicolumn{7}{|c|}{ Nutrientes totais } \\
\hline & $\mathrm{N}-\mathrm{NH}_{4}^{+}$ & $\mathrm{N}-\mathrm{NO}_{3}$ & $\mathrm{~N}^{(2)}$ & $\mathrm{Ca}^{(3)}$ & $\mathrm{P}^{(3)}$ & $\mathrm{K}^{(3)}$ & $\mathrm{Fe}^{(3)}$ & $\mathrm{Mn}^{(3)}$ & $\mathrm{Zn}^{(3)}$ \\
\hline $\mathrm{m}^{3} \mathrm{ha}^{-1}$ & 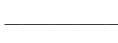 & & & 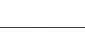 & $a^{-1}$ & & & & \\
\hline 25 & 0,53 & 2,83 & 28 & 962 & 168 & 63 & 55 & 7 & 1,0 \\
\hline 50 & 1,06 & 5,66 & 56 & 1.923 & 336 & 126 & 111 & 14 & 1,5 \\
\hline 75 & 1,59 & 8,49 & 84 & 2.885 & 504 & 189 & 166 & 20 & 2,0 \\
\hline 100 & 2,12 & 11,32 & 112 & 3.847 & 672 & 253 & 221 & 27 & 2,5 \\
\hline
\end{tabular}

(1) Densidade de $0,40 \mathrm{Mg} \mathrm{m}^{-3}$ e $42,1 \%$ de matéria seca. ${ }^{(2)}$ Determinado pela metodologia de Tedesco et al. (1995). ${ }^{(3)}$ Total do nutriente determinado por espectrometria de fluorescência de raios X por energia dispersiva, conforme Wastowski et al. (2010).

O milho (cultivar AS-1555YG) foi semeado no dia 21 de novembro de 2010, no espaçamento de $0,40 \mathrm{~m}$ entre as linhas e com população final de 75.000 plantas ha $^{-1}$. Para o tratamento com NPK, foi utilizada adubação para expectativa de rendimento de $6.000 \mathrm{~kg} \mathrm{ha}^{-1}$ (CQFS-RS/SC 2004). Na semeadura, foram aplicados $25 \mathrm{~kg} \mathrm{ha}^{-1}$ de $\mathrm{N}, 85 \mathrm{~kg} \mathrm{ha}^{-1}$ de $\mathrm{P}_{2} \mathrm{O}_{5}$ e $50 \mathrm{~kg} \mathrm{ha}^{-1} \mathrm{de} \mathrm{K}_{2} \mathrm{O}$, na forma de ureia, superfosfato triplo e cloreto de potássio, respectivamente. Em cobertura, nos estádios V4 a V5, foram aplicados $60 \mathrm{~kg} \mathrm{ha}^{-1}$ de N, na forma de ureia, a lanço e sem incorporação ao solo. Durante todo o ciclo, ocorreu precipitação total de $700 \mathrm{~mm}$, bem distribuídos (Figura 1b), quantidade adequada para as necessidades da cultura, que é de 500-800 mm (Landau \& Guimarães 2010).

As produtividades de grãos da cultura do girassol e do milho foram determinadas no centro das parcelas, em área útil de 7,2 $\mathrm{m}^{2}$ e 3,2 $\mathrm{m}^{2}$, respectiva- mente, com umidade dos grãos corrigida para $13 \%$. As variáveis explicativas, avaliadas na cultura do milho, foram: comprimento de espiga (CE), diâmetro da espiga (DE), diâmetro de sabugo (DS), número de grãos por fileira (NGF), número de fileiras por espiga (NFE) avaliadas em 10 espigas por parcela e peso de mil grãos (PMG) (Brasil 2009).

Os resultados foram submetidos à análise de variância (teste $F, p<0,05$ ) e, quando significativos para os fatores qualitativos, as médias foram comparadas pelo teste dos contrastes ortogonais, a 5\%. Para os fatores quantitativos, realizou-se análise de regressão, a 5\%, utilizando-se o programa estatístico SAS.

\section{RESULTADOS E DISCUSSÃO}

A produtividade de grãos de girassol aumentou linearmente com as doses de RIC, variando de $479 \mathrm{~kg} \mathrm{ha}^{-1}$, na dose de zero, a $1.014 \mathrm{~kg} \mathrm{ha}^{-1}$, na
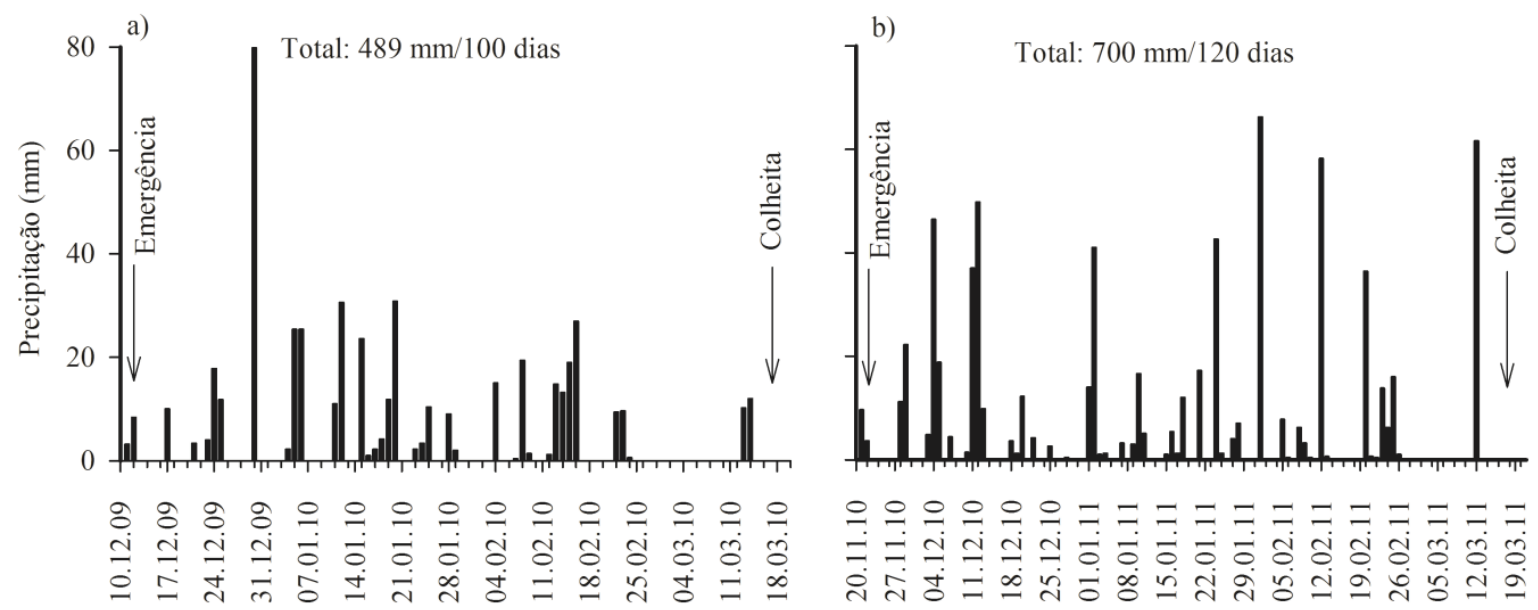

Intervalo de datas

Figura 1. Precipitação diária e total ocorridas na área experimental, durante o cultivo de girassol (a) (2009/2010) e milho (b) (2010/2011) (Frederico Westphalen, RS, 2014). 
maior dose de resíduo, representando incremento de $535 \mathrm{~kg} \mathrm{ha}^{-1}$ (Figura 2a). No tratamento com NPK, a produtividade de grãos foi de $585 \mathrm{~kg} \mathrm{ha}^{-1}$, equivalente à aplicação de $20 \mathrm{~m}^{3} \mathrm{ha}^{-1}$ de resíduo. Observou-se baixo rendimento de grãos, independentemente da dose utilizada.

No tratamento com adubação mineral, foram aplicadas doses de NPK, para uma expectativa de rendimento de $2.000 \mathrm{~kg} \mathrm{ha}^{-1}$ de grãos, sendo atingido, aproximadamente, $50 \%$ desse valor. Isso mostra que outros fatores podem ter influenciado no baixo rendimento de grãos obtido e comprometido o efeito das adubações, como, por exemplo, a época de semeadura da cultura, realizada em dezembro, conforme também observado por Zaffaroni \& Grigolo (1998). Apesar disso, o resíduo orgânico apresentou potencial fertilizante, com rendimentos superiores aos da adubação mineral (Tabela 2).
Na cultura do milho, ocorreram aumentos na produtividade de grãos, em função do incremento nas doses de RIC. A máxima produtividade de grãos de milho, com o uso de RIC, foi obtida com a dose de $90,3 \mathrm{~m}^{3} \mathrm{ha}^{-1}$, correspondendo à produtividade de grãos de $9.839 \mathrm{~kg} \mathrm{ha}^{-1}$ (Figura 2b). Portanto, o máximo incremento na produtividade de grãos, em relação à ausência de adubação, foi de $2.568 \mathrm{~kg} \mathrm{ha}^{-1}$ e a produtividade equivalente a $86 \%$ da obtida com a adubação mineral.

Apesar de haver maior adição de nitrogênio nos tratamentos com doses de RIC superiores a $76 \mathrm{~m}^{3} \mathrm{ha}^{-1}$, a quantidade de nitrogênio disponível (amônio e nitrato) foi menor, em relação à adubação mineral. No resíduo orgânico, em média, $12 \%$ do nitrogênio total apresentou-se na forma mineral, sendo esse o nutriente que mais limita a produtividade da cultura (Gastal \& Lemaire 2002). Possivelmente, as

Tabela 2. Contrastes ortogonais comparando doses de resíduo de indústria de carnes (RIC) com a adubação mineral (Frederico Westphalen, RS, 2014).

\begin{tabular}{|c|c|c|c|c|c|c|}
\hline \multirow{2}{*}{ Contrastes } & \multicolumn{5}{|c|}{ Doses de RIC $\left(\mathrm{m}^{3} \mathrm{ha}^{-1}\right)$} & \multirow{2}{*}{$\begin{array}{c}\text { Adubação } \\
\text { mineral (NPK) }\end{array}$} \\
\hline & 0 & 25 & 50 & 75 & 100 & \\
\hline & \multicolumn{5}{|c|}{ - Girassol } & \\
\hline Rendimento grãos $\left(\mathrm{kg} \mathrm{ha}^{-1}\right)$ & $456^{\mathrm{ns}}$ & $606^{\mathrm{ns}}$ & $832^{\text {ns }}$ & $815^{\mathrm{ns}}$ & $1.020^{*}$ & 584 \\
\hline & & & & & & \\
\hline Rendimento grãos $\left(\mathrm{kg} \mathrm{ha}^{-1}\right)$ & $7.271^{*}$ & $9.147^{\mathrm{ns}}$ & $9.503^{\mathrm{ns}}$ & $9.104^{\text {ns }}$ & $10.126^{\mathrm{ns}}$ & 11.393 \\
\hline Comprimento espiga $(\mathrm{cm})$ & $11,30^{*}$ & $13,17^{\mathrm{ns}}$ & $13,42^{\text {ns }}$ & $13,09^{\text {ns }}$ & $13,66^{\mathrm{ns}}$ & 13,88 \\
\hline Número grãos por fileira & $29,70 *$ & $35,13^{\mathrm{ns}}$ & $35,30^{\mathrm{ns}}$ & $34,67^{\mathrm{ns}}$ & $36,33^{\mathrm{ns}}$ & 37,43 \\
\hline Número grãos por espiga & $417,9 *$ & $478,4^{\mathrm{ns}}$ & $509,1^{\text {ns }}$ & $497,7^{\text {ns }}$ & $522,0^{\mathrm{ns}}$ & 519,33 \\
\hline Diâmetro espiga $(\mathrm{cm})$ & $4,42^{\mathrm{ns}}$ & $4,55^{\mathrm{ns}}$ & $4,55^{\mathrm{ns}}$ & $4,63^{\mathrm{ns}}$ & $4,68^{\mathrm{ns}}$ & 4,56 \\
\hline Diâmetro sabugo (cm) & $2,41^{\mathrm{ns}}$ & $2,61^{\text {ns }}$ & $2,51^{\mathrm{ns}}$ & $2,45^{\mathrm{ns}}$ & $2,47^{\mathrm{ns}}$ & 2,41 \\
\hline Número fileiras por espiga & $14,1^{\mathrm{ns}}$ & $13,6^{\mathrm{ns}}$ & $14,4^{\mathrm{ns}}$ & $14,4^{\mathrm{ns}}$ & $14,4^{\mathrm{ns}}$ & 13,9 \\
\hline
\end{tabular}

* Significativo pelo teste dos contrastes ortogonais, a $5 \%$; ${ }^{\text {ns }}$ não significativo.

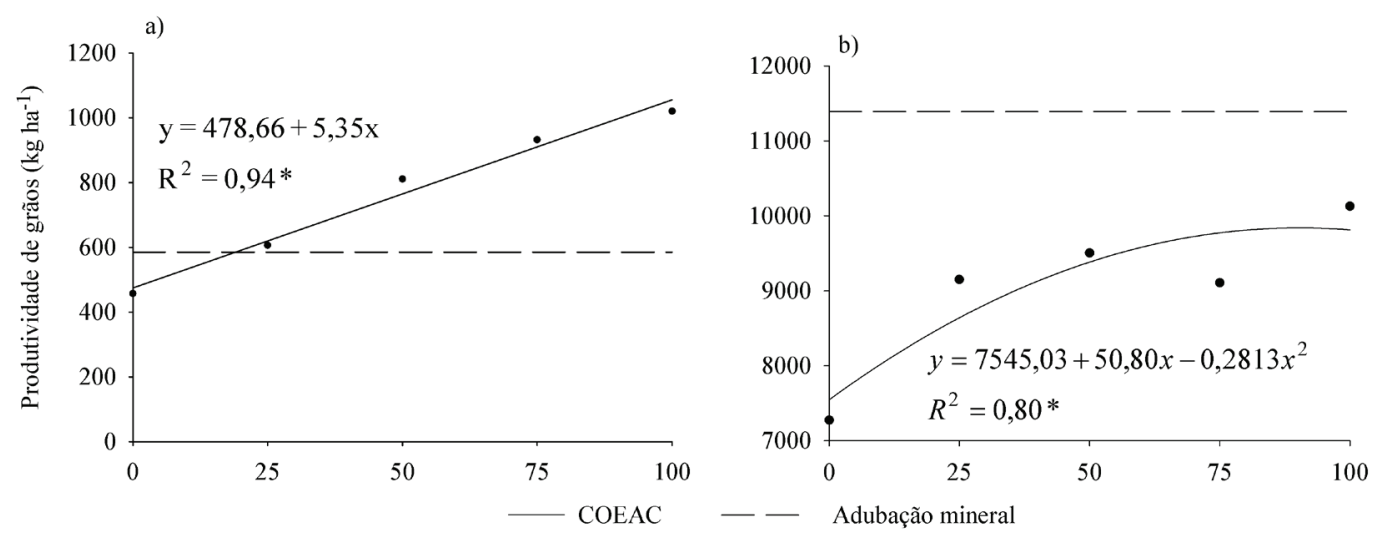

Doses de resíduos de indústria de carnes $\left(\mathrm{m}^{3} \mathrm{ha}^{-1}\right)$

Figura 2. Equação de regressão para a produtividade de grãos de girassol (a) e de milho (b), em função de doses de resíduo de indústria de carnes (RIC) e adubação mineral (Frederico Westphalen, RS, 2014). * Significativo pelo teste F $(\mathrm{p}<0,05)$. 
quantidades de $\mathrm{N}$ mineral foram determinantes para as produtividades obtidas.

A dose equivalente de RIC para obter a máxima produtividade de grãos $\left(90,3 \mathrm{~m}^{3} \mathrm{ha}^{-1}\right)$ esteve próxima aos valores encontrados por Konzen (2003), em que as maiores produtividades de grãos foram obtidas entre as doses de $75 \mathrm{~m}^{3} \mathrm{ha}^{-1}$ e $100 \mathrm{~m}^{3} \mathrm{ha}^{-1} \mathrm{de}$ resíduo orgânico. Já Pauletti et al. (2008) e Silva et al. (2008) verificaram maior produtividade de grãos de milho com doses de resíduo orgânico próximas a $50 \mathrm{~m}^{3} \mathrm{ha}^{-1}$. A diferença entre as quantidades de resíduo orgânico, para obter a máxima produtividade de grãos, pode ser atribuída à variação inicial de nutrientes nos solos dos experimentos e teor de nutrientes presente nos resíduos.

Aumentos de produtividade de grãos foram observados com o uso de dejetos líquidos de suínos, em Argissolo Vermelho cultivado com milho (Ceretta et al. 2005), e com o uso de dejetos líquidos de bovinos, em Latossolo com a cultura do trigo (Pauletti et al. 2008). Além disso, o uso de composto orgânico de cama de aviário em Argissolo, na cultura da alface, favoreceu o incremento na produção de sua massa verde (Santos et al. 2001).

Nesse sentido, alguns trabalhos indicam que foi possível aumentar a disponibilidade de nutrientes, por meio do uso de resíduos orgânicos (Konzen 2003, Ceretta et al. 2005, Figueiredo \& Filho 2007, Nobre et al. 2010). No entanto, ainda é preciso definir doses que possibilitem aumento na produtividade das culturas, associadas a critérios de segurança que permitam o uso desses resíduos orgânicos sem o risco de poluição ambiental, para diferentes condições de solo e clima.

Para as variáveis diâmetro de sabugo e número de fileiras por espiga, não houve efeito das doses de RIC. Pode-se, então, inferir que as doses de RIC não atuaram significativamente sob essas varáveis, demonstrando que, nessas condições de solo, prevalece a dependência das variáveis genéticas, não havendo alteração em função da disponibilidade de nutrientes no solo (Heinrichs et al. 2003). Contrariamente, os demais componentes de rendimento apresentaram resposta à aplicação das doses de RIC (Figura 3).
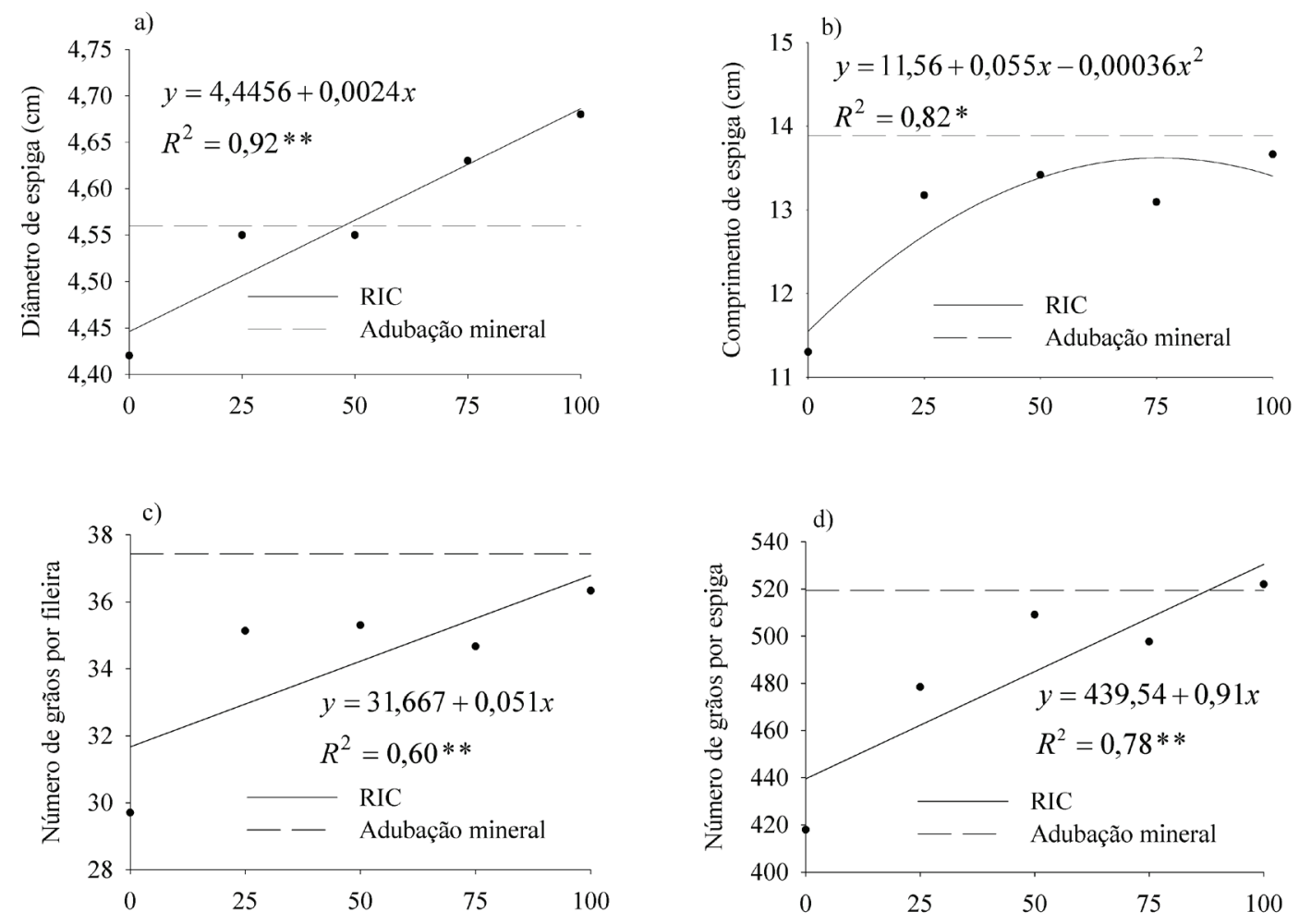

Doses de resíduos de indústria de carnes $\left(\mathrm{m}^{3} \mathrm{ha}^{-1}\right)$

Figura 3. Equações de regressão para as variáveis explicativas: a) diâmetro de espiga; b) comprimento de espiga; c) número de grãos por fileira; d) número de grãos por espiga, com a aplicação de doses de resíduo de indústria de carnes (RIC) e adubação mineral (Frederico Westphalen, RS, 2014). ** Significativo pelo teste $\mathrm{F}(\mathrm{p}<0,01)$; * Significativo pelo teste $\mathrm{F}(\mathrm{p}<0,05)$. 
Para as variáveis diâmetro de espiga, número de grãos por fileira e número de grãos por espiga, o incremento foi linear, com o aumento nas doses de RIC, mostrando que o RIC apresenta potencial fertilizante. Assim, a hipótese de que o RIC apresenta potencial nutricional para as culturas pode ser confirmada por meio da comparação entre os resultados obtidos com as doses de RIC, em relação à adubação mineral, nas culturas de girassol e de milho (Tabela 2).

O comprimento de espiga aumentou com as doses, atingindo valor máximo com $76 \mathrm{~m}^{3} \mathrm{ha}^{-1}$ de resíduo (Figura 3). Observou-se que a curva de resposta foi similar à do rendimento de grãos (Figura 2b), mostrando que a delimitação das doses foi adequada para avaliar o potencial fertilizante do resíduo. No entanto, o decréscimo nos valores, após atingir o valor máximo, indica aplicações excessivas de elementos, podendo causar contaminação do solo. O RIC apresenta potencial fertilizante, no entanto, para a delimitação da dose adequada, é necessário considerar o seu potencial poluente.

\section{CONCLUSÕES}

1. O resíduo de indústria de carnes proporcionou aumentos na produtividade de grãos de girassol e de milho, em relação à testemunha sem adubação. A máxima produtividade de grãos de milho foi obtida com a dose de $87 \mathrm{~m}^{3} \mathrm{ha}^{-1}$, equivalendo a $92 \%$ da produtividade de grãos obtida com a adubação mineral.

2. Na cultura do girassol, o uso de doses de resíduo de indústria de carnes superiores a $20 \mathrm{~m}^{3} \mathrm{ha}^{-1}$ proporcionou incrementos na produtividade de grãos, em relação à adubação mineral.

3. O resíduo de indústria de carnes apresentou potencial agrícola para disponibilizar nutrientes em Latossolo Vermelho.

\section{REFERÊNCIAS}

AITA, C. et al. Plantas de cobertura de solo como fonte de nitrogênio ao milho. Revista Brasileira de Ciência do Solo, Viçosa, v. 25, n. 1, p. 157-165, 2001.

BISCARO, G. A. et al. Adubação nitrogenada em cobertura no girassol irrigado nas condições de Cassilândia - MS. Ciência e Agrotecnologia, Lavras, v. 32, n. 5, p. 13661373, 2008.

BRASIL. Ministério da Agricultura, Pecuária e Abastecimento. Secretaria de Defesa Agropecuária.
Regras para análise de sementes. Brasília, DF: MAPA/ ACS, 2009.

BUGBEE, B. G.; SALISBURY, F. B. Exploring the limits of crop productivity: I. Photosynthetic efficiency of wheat in high irradiance environments. Plant Physiology, Rockville, v. 88, n. 3, p. 869-878, 1988.

CASTRO, C.; FARIAS, J. R. B. Girassol no Brasil: ecofisiologia do girassol. Londrina: Embrapa Soja, 2005.

CERETTA, C. A. et al. Produtividade de grãos de milho, produção de matéria seca e acúmulo de nitrogênio, fósforo e potássio na rotação aveia preta/ milho/ nabo forrageiro com aplicação de dejeto líquido de suínos. Ciência Rural, Santa Maria, v. 35, n. 6, p. 1287-1295, 2005.

COMISSÃO DE QUÍMICA E FERTILIDADE DO SOLO - RS/SC (CQFS-RS/SC). Manual de adubação e calagem para os Estados do Rio Grande do Sul e de Santa Catarina. 10. ed. Porto Alegre: SBCS/UFRGS, 2004.

DOBLINSKI, A. F. et al. Nonpoint source pollution by swine farming wastewater in bean crop. Revista Brasileira de Engenharia Agrícola e Ambiental, Campina Grande, v. 14, n. 1, p. 87-93, 2010.

FERNANDES, M. F. et al. Características físico-químicas e perfil lipídico do leite de cabras mestiças Moxotó alimentadas com dietas suplementadas com óleo de semente de algodão ou de girassol. Revista Brasileira de Zootecnia, Brasília, DF, v. 37, n. 4, p. 703-710, 2008.

FIGUEIREDO, T. L.; GRASSI FILHO, H. Níveis de lodo de esgoto na produtividade do girassol. Revista de la Ciencia del Suelo y Nutrición Vegetal, Temuco, v. 7, n. 3, p. 16-25, 2007.

GASTAL, F.; LEMAIRE, G. N uptake and distribution in crops: an agronomical and ecophysiological perspective. Journal of Experimental Botany, Lusignan, v. 53, n. 370, p. 789-799, 2002.

GIACOMINI, S. J.; AITA, C. Cama sobreposta e dejetos líquidos de suínos como fonte de nitrogênio ao milho. Revista Brasileira de Ciência do Solo, Viçosa, v. 32, n. 1, p. 195-205, 2008.

HEINRICHS, R. et al. Doses de nitrogênio em cobertura na cultura do milho. Revista Científica Eletrônica de Agronomia, Garça, v. 2, n. 4, p. 1-5, 2003.

INSTITUTO BRASILEIRO DE GEOGRAFIA E ESTATÍSTICA (IBGE). Lavouras. 2011. Disponível em: $<$ http://www.ibge.gov.br/home/estatistica/indicadores/ agropecuaria/lspa/>. Acesso em: 01 jul. 2011.

KONZEN, A. E. Aproveitamento de dejetos líquidos de suínos para fertirrigação e fertilização em grandes culturas. Sete Lagoas: Embrapa Milho e Sorgo, 2003. (Circular técnica, 32). 
LANDAU, E. C.; GUIMARÃES, D. P. Cultivo do milho: zoneamento agrícola. 2010. Disponível em: $<\mathrm{http}: / / \mathrm{www}$. cnpms.embrapa.br/publicacoes/milho_6_ed/zoneamento. htm>. Acesso em: 28 mar. 2012.

LOBO, T. F. et al. Efeito do nitrogênio e do lodo de esgoto nos fatores produtivos do feijoeiro. Revista Ceres, Viçosa, v. 59, n. 1, p. 118-124, 2012.

MORAES, M. T.; SILVA, V. R.; ARNUTI, F. Resíduos líquidos de efluentes de agroindústria de carnes na produtividade do girassol. Enciclopédia Biosfera, Goiânia, v. 8, n. 14, p. 843-853, 2012.

NOBRE, R. G. et al. Produção de girassol sob diferentes lâminas com efluentes domésticos e adubação orgânica. Revista Brasileira de Engenharia Agrícola e Ambiental, Campina Grande, v. 14, n. 7, p. 747-754, 2010.

PAUleTti, V. et al. Produtividade de culturas sob diferentes doses de esterco líquido de gado de leite e adubação mineral. Scientia Agraria, Curitiba, v. 9, n. 2, p. 199-205, 2008.

SANTOS, R. H. S. et al. Efeito residual da adubação com composto orgânico sobre o crescimento e produção de alface. Pesquisa Agropecuária Brasileira, Brasília, DF, v. 36, n. 11, p. 1395-1398, 2001.
SILVA, R. G. et al. Produtividade de variedades de milho nos sistemas de cultivo orgânico e convencional. Revista Caatinga, Mossoró, v. 21, n. 2, p. 78-85, 2008.

SILVEIRA, F. de M. et al. Dejeto líquido bovino em plantio direto: perda de carbono e nitrogênio por escoamento superficial. Revista Brasileira de Ciência do Solo, Viçosa, v. 35, n. 5, p. 1759-1768, 2011.

TEDESCO, M. J. et al. Análise de solos, plantas e outros materiais. 2. ed. rev. e ampl. Porto Alegre: UFRGS, 1995.

TSUZUKI, E. T. et al. Utilization of sunflower seed in laying hen rations. Brazilian Journal of Poultry Science, Campinas, v. 5, n. 3, p. 179-182, 2003.

WASTOWSKI, A. D. et al. Caracterização dos níveis de elementos químicos em solo submetido a diferentes sistemas de uso e manejo, utilizando espectrometria de fluorescência de raios X por energia dispersiva (EDXRF). Química Nova, São Paulo, v. 33, n. 7, p. 1449-1452, 2010.

ZAFFARONI, E.; GRIGOLO, S. C. Determinação da época de plantio do girassol na região sul do Rio Grande do Sul. Revista Brasileira de Agrociência, Pelotas, v. 2 , n. 2, p. 138-142, 1998. 